\title{
THE ACOUSTICS OF FLOORS IN CONDOMINIUMS
}

\author{
Marshall Long ${ }^{1}$ \\ Marshall Long/Acoustics \\ Sherman Oaks, California 91423
}

$\mathrm{J}$ oe Stewart ${ }^{2}$ and his wife Ellen recently purchased a condominium in an upscale neighborhood in Playa del Mar, CA. The location was excellent, less than a mile from the beach, south of Marina del Rey. The condominium was comfortable, about 1600 square feet, and the builder had a reputation for quality. Unfortunately, even with a $\$ 700,000$ price tag, the noise problems were considerable. Movements of people upstairs, both footfall on the hard surface floors and walking on carpeted floors, were loud enough to wake

"People want their

apartments and

condominium homes to be

quiet and free from

intrusions, just like a single-

family residence, but the

reality is quite different." causes the floor to deflect like a trampoline as he pads along. Floor squeak sounds like a birdcall, which produces noise by metal rubbing on wood.

Most floor-ceiling noise problems fall into one or more of these categories although occasionally there are structurally transmitted sounds due to equipment, doors or drawers closing, or furniture sliding along the floor.

\section{Airborne noise}

Airborne noise is created in one space and is transmitted through the air and through an intervening partition were flushed upstairs, it sounded like a waterfall running through their walls. The closing of doors, cabinets, and drawers could all be clearly heard. Walking in the upstairs hallway was plainly audible.

Situations such as these are increasingly common in Los Angeles, where the city building department and elected officials refuse to enforce the State's building codes on noise. Even if they were enforced, they are so anemic that minimum code compliance does not yield a quiet living environment. In fact when Stewart complained to the builder, subsequent acoustical tests showed the building to be in compliance (barely) with California minimum code standards.

As a growing population is extruded into highly urbanized areas, multifamily dwellings have become the most common way of packing more people into less space. Pressures of population and cost force people together, and noise and noise transmission between occupied spaces are significant concerns. People want their apartment and condominium homes to be quiet and free from intrusions, just like a single-family residence, but the reality is quite different.

\section{Floor ceiling noise transmission}

The most common noise and vibration problem in condominiums is transmission through floor-ceilings and it falls into four categories: 1) airborne, 2) footfall, 3) structural deflection, and 4) floor squeak. Plumbing noise is also a factor particularly when plastic piping is used in waste stacks or when pipes are undersized and not vibrationally isolated from the structure.

Airborne noise can be generated by neighbors' frank exchange of views (diplospeak for a spat), or by a Kiss concert played on their child's stereo. Footfall noise is generated by heel impacts, like having a flamenco dancer upstairs. Structural deflection is slightly different-like having a sumo wrestler upstairs, who even though he may be barefoot, still into the adjacent space. Sources might include TV, stereo systems, or simple conversation. The isolation of airborne noise such as speech is well characterized by the Sound Transmission Class (STC) rating. The STC rating is the result of a test performed in accordance with ASTM E 90 or ISO 140 laboratory test standards. To do the test a partition is built into a heavy wall separating two concrete test chambers in a laboratory. A standard sound is created in one room, called the source room, and transmitted through the partition and into the receiver room. The difference between the levels in the source and receiver room, adjusted for the area of the partition and the absorption in the receiver room is the transmission loss in decibels. The measured transmission loss values in 16 third-octave frequency bands are compared to a standard curve (ASTM E413) to determine the STC rating. The higher the STC rating, the better the partition is at stopping airborne noise. Under field (F) conditions the measured FSTC rating is about five points lower than the laboratory rating, and this difference is acknowledged in the building codes. Thus if an STC 50 is the required laboratory rating, a field test of 45 is equivalent. In California the test procedure has been diluted by eliminating the inclusion of the correction for the absorption in the receiving room

\section{Reasonable expectation of the buyer}

In selecting the appropriate design criterion for a given level of quality, the designer should consider the type of building and the level of quality expected by the buyer. As the perceived quality of a residence increases, so too do the expectations for a quiet environment. This expectation of quality may be based on cost, location, sales information provided to the buyer, or because a person is purchasing a permanent home rather than renting an apartment. Unfortunately, too often builders put money into the appearance of a residential building but little into noise iso- 
lation. The words luxury, high quality, or soundproof are sometimes used to describe projects that barely meet, or even fail to meet minimum code requirements. If builders plan to characterize their product in this manner, they are well advised to provide a level of noise control commensurate with the description. Multifamily dwellings can be grouped into the three quality categories in Table 1.

Table 1. Level of quality vs type of use

$\begin{array}{ll}\text { Classification } & \text { Residential Use } \\ \text { Minimum Quality } & \begin{array}{l}\text { Normal Apartments } \\ \text { Nursing Homes }\end{array} \\ & \text { Hospitals } \\ \text { Medium Quality } & \begin{array}{l}\text { Good Apartments } \\ \text { Normal Condominiums }\end{array} \\ \text { High Quality } & \text { High Quality Condominiums }\end{array}$

Low-cost rental property, subsistence housing, and temporary housing such as hotels and motels would be designed to the minimum-quality level. Note that the minimum-quality design level is not the same as minimum-code level, since there must be a certain safety factor included to insure code compliance. If one were to design exactly to the code minimum, it would mean that the selected construction would have a $50 \%$ probability of passing a field test. This is not good design practice and since test results for a given wall or floor will vary by a few points, a 3-5 dB margin of safety is recommended. It is also prudent to examine the range of test results for a given configuration and to expect the lowest values in the test range rather than the highest.

The medium-quality level is appropriate for use in highquality apartments and normal condominiums. A first-time condominium purchaser may be moving from a single family home and have an expectation of quality based on his or her previous history. Any condominium should be designed to at least the medium quality standard. If noise problems arise, the owner of a condominium does not have the freedom of movement of an apartment dweller. Under California law the seller of a condominium must reveal any known defects to a potential buyer, including any noise problems.

Condominium homes where there is the expectation of a level of isolation similar to that found in a detached singlefamily residence fall into the high-quality category. In these cases due in part to the location, cost, and sales representation, owners may express dissatisfaction if they can hear any activities in adjacent dwelling units. They are particularly sensitive to footfall and plumbing noise since these may occur relatively frequently.

\section{Airborne noise standards}

Many cities and states have adopted standards for the STC ratings in multifamily dwellings and these can be used to develop prudent design objectives for various levels of construction quality. The legally mandated minimum STC ratings are usually set to 50 (State of California, 1974 and the Uniform Building Code (UBC) Appendix Chapter 35, 1982) however in some cases stricter standards have been adopted. For example the City of Redondo Beach, CA requires a minimum STC of 55 in condominium homes.

An STC 50 may be the code required rating for a given partition. This does not necessarily mean that it yields acoustical privacy between units or that it represents a level of quality that guarantees owner satisfaction. Rather minimum code construction is so bad that there has to be a law against building it any worse. Other criteria such as reasonable expectation of the buyer should be used as the basis for construction decisions. Table 2 shows STC ratings for various levels of construction quality in multifamily dwellings. These ratings apply to both walls and floor-ceiling separations and are based on reasonable expectation of quality.

Table 2. Sound Transmission Class vs Level of Quality For Party Wall and Floor-Ceiling Construction

$\begin{array}{lcc}\text { Classification } & \text { STC } & \frac{\text { FSTC }}{45} \\ \text { Minimum Code } & 50 & 50 \\ \text { Minimum Quality } & 55 & 55 \\ \text { Medium Quality } & 60 & 60 \\ \text { High Quality } & 65 & \end{array}$

\section{Structures for airborne noise isolation}

High transmission loss values can be obtained by using two approaches: a high-mass single panel or a low-mass, decoupled, double panel. A simple concrete slab of sufficient thickness can provide a good floor-ceiling. A 6 inch (152 $\mathrm{mm}$ ) thick slab has an STC rating of 55 and is sufficient by itself for a minimum quality floor. Six-inch concrete slabs with a wire-hung drywall ceiling and fiberglass insulating batt can provide enough isolation for airborne noise to be used in medium quality construction. For high quality construction, even with concrete slabs, a drywall ceiling suspended from neoprene isolators is required.

With double panel construction there is a complicated tradeoff among the partition masses, the panel spacing, and the degree of decoupling. Highly rated double-panel floor-ceilings combine a high-mass floor with a large separation between the floor and the ceiling below. The airspace space between contains fiberglass batt insulation usually 6 inch thick. The two panels should be structurally decoupled either with separate structural supports or by means of a resiliently supported ceiling or floating floor.

In wood construction, the structures are light and stiff. The problem with wood floors for airborne noise isolation is in achieving sufficient mass and decoupling. Lightweight-concrete fill, which weighs 110 to $115 \mathrm{lbs} / \mathrm{cu} \mathrm{ft}$ $(540-560 \mathrm{~kg} / \mathrm{sq} \mathrm{m})$ and should be poured to a thickness of 1.5 inches $(38 \mathrm{~mm})$, is a common way of increasing the floor mass. Composite floor-ceiling systems fall somewhere in between wood and concrete. A composite floor can be constructed using a 3 inch $(75 \mathrm{~mm})$ concrete fill poured into a webbed sheet metal deck with a suspended ceiling below. With this configuration, a drywall ceiling is required even for the minimum quality design standard. Figure 1 gives examples of floor-ceiling systems suitable for medium quality construction. 


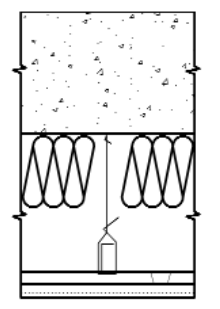

6" (150 mm) Solid Conerete Panel

$75 \mathrm{lbs} / \mathrm{sq}$ pt (365 kg/sq m)

R-11 (3.5" or $90 \mathrm{~mm})$ Batt Insulation

1 Layer 5/8" (16 mm) Gypsum Board

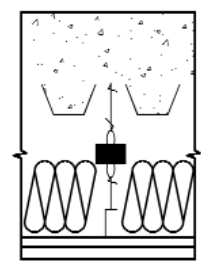

3" (75 mm) Thick Concrete on Metal Decking

(36 lbs/sq pt or $176 \mathrm{~kg} / \mathrm{sq} \mathrm{m}$ )

16" (400 mm) Airspace

R-11 Batt (3.5" or $90 \mathrm{~mm}$ ) Insulation

$0.15^{\prime \prime}$ Deplection Neoprene Isolators

$5 / 8$ " (16 mm) Sypsum Board on Hat Channel

and Carrying Channel

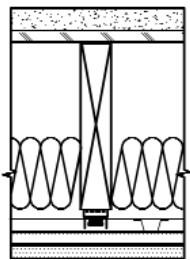

1 1/2" (38 mm) Lightweight Concrete

(110 lbs/cu pt or $1760 \mathrm{~kg} / \mathrm{cu} \mathrm{m}$ )

1 Layer 3/4" (19 mm) Plywood Glued and Screw Nalled

$2(50 \mathrm{~mm}) \times$ Wood Jolsts

R-11 (3.5" or $90 \mathrm{~mm}$ ) Batt Insulation

RSIC-1 lsolators with $7 / 8$ " Hat Channel

2 Layers 5/8" (16 mm) Gypsum Board

Fig. 1. Types of floor-ceiling assemblies for medium quality STC ratings

\section{Footfall noise}

The act of walking across a floor generates noise due to two mechanisms: footfall and structural deflection. Footfall noise is created by the impact of a hard object, such as a heel, striking the surface of a floor. A heel is relatively lightweight and the noise associated with its fall is considered separately from the transfer of weight due to walking. Impact noise can be measured using a standard tapping machine as a source, which leads to an Impact Insulation Class (IIC) rating. The IIC test measures the reaction of a floor system to a series of small hammers dropped from a standard height. Although this may accurately characterize the noise of a heel tap against the floor surface, it does not measure the effect of loading and unloading under the full weight of a walker. Thus the achievement of a particular IIC rating in a given floor-ceiling system does not guarantee that footfall noise will not be a problem, or that the sound of walking will not be audible in the spaces below.

The level of impact noise in the receiving space is primarily dependent on the softness of the floor covering, and is best attenuated using a thick carpet and pad. Hard surface floors must be installed on thick resilient underlayerments and used in conjunction with a vibrationally-isolated ceiling to achieve medium quality results.

\section{Impact Insulation Class-IIC}

The Impact Insulation Class (IIC) is a laboratory rating much like the Sound Transmission Class; however, it represents the isolation provided by a floor system subjected to a controlled impulsive load. Since there is no standard footstep, the impulsive loads are generated by a tapping machine consisting of a row of five cylindrical hammers, each weighting a half-kilogram (1.1 lbs), which are raised by a cam mechanism and dropped sequentially from a height of $4 \mathrm{~cm}$ (1.6 inch) onto the surface of the floor at a rate of 10 impacts per second. There are test standards in the United States and in Europe that regulate the laboratory (ASTM E 492 and ISO 140/6) as well as field (ASTM E 1007 and ISO 140/7) test methodologies. Spatially averaged sound pressure levels measured in the room below are adjusted for the absorption in the receiving room and compared to standard values to obtain an overall rating.

Minimum IIC ratings are set to 50 in the UBC with a minimum field tested FIIC of 45 allowed. At this rating, footfall noise is quite pronounced and very audible in the unit below. In response some cities and condominium associations have adopted more stringent laws. The City of Redondo Beach, for example, sets a minimum IIC rating of 65 in condominiums. Other cities such as Beverly Hills control noise through a property line ordinance. The point at which footfall-generated impact noise becomes inaudible is closer to an IIC of 75 . The level of quality due a buyer in the control of impact-generated noise is numerically higher than that for airborne noise.

Table 3. Impact Insulation Class vs Level of Construction for Party Floor-Ceiling Construction

$\begin{array}{lll}\text { Classification } & \underline{\text { IIC }} & \underline{\text { FIIC }} \\ \text { Minimum Code } & 50 & 45 \\ \text { Minimum Quality } & 55 & 50 \\ \text { Medium Quality } & 65 & 60 \\ \text { High Quality } & 75 & 70\end{array}$

\section{Floor coverings}

It is relatively easy to achieve high impact insulation class ratings by using carpet and pad. Medium quality ratings are achievable with a vinyl floor surface on a 1/2 inch rubber mat. When hard surface materials such as quarry tile, marble, or hardwood floors are installed, low impact ratings are obtained unless relatively thick (1 inch) isolating underlayerments are utilized. A number of products are commercially available, which are intended as resilient underlayments for hard surfaced flooring. Thin layers of resilient material such as fiberglass board, cardboard-like materials, and wire mesh mats can raise the IIC ratings modestly, three to five points
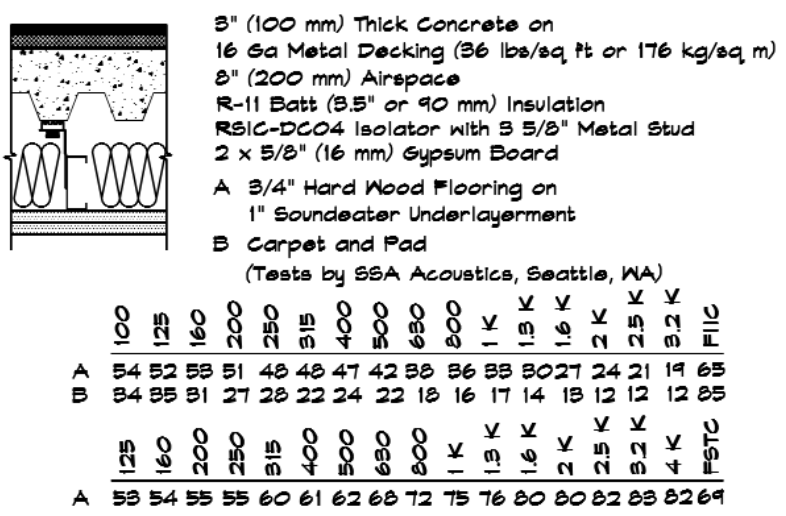

Fig. 2. Isolated-composite floor-ceiling 
above minimum code, but seldom provide sufficient deflection to achieve the impact isolation necessary for condominium construction. Thicker fiberboard or composite rubber mats give better results.

A medium quality composite floor construction, shown in Fig. 2, might consist of 3/4 inch hardwood flooring on a 1 inch thick resilient underlayer, on 3 inch concrete on steel deck on joists. When combined with a double 5/8 inch drywall ceiling supported on hat channel and neoprene isolators these constructions can provide IIC ratings in the medium quality range.

Where the appearance of wood or tile is desired, the hard surface can be used in non-walking areas such as within 1 to 2 feet $(0.3-0.6 \mathrm{~m})$ of a wall with carpet installed where walking traffic occurs. In kitchen and bathroom areas, hard tile over a thick backing material can provide reasonable IIC ratings when combined with a point-mounted resiliently suspended ceiling. In all cases, engineers should refer to laboratory tests published by the manufacturers.

\section{Structural deflection}

The achievement of a high IIC rating in a given floorceiling system does not guarantee that noise will not be a problem or that the sound of walking will not be audible in the units below. The IIC test measures the reaction of a floor system to the impact of a series of $1.1 \mathrm{lb}(0.5 \mathrm{~kg})$ weights dropped on the surface. Although this may model the noise of a heel tap, it does not represent the full effect of the loading and unloading under the weight of a walker. When people step or even stand on a floor, it will deflect under the static and dynamic load of their weight. If the underside of the floor is exposed to the room below, a sound generated by this motion will radiate directly into the receiving space. Noise generated by floor deflection sounds like low-frequency thumps, whereas heel strikes create high frequency clicks.

Three mechanisms are available to improve this condition: 1) increase the stiffness of the floor system, 2) increase the structural damping, and 3) increase the vibrational decoupling between the floor and the ceiling. In concrete structures both the stiffness and damping increase with slab thickness. For the 6 inch $(152 \mathrm{~mm})$ concrete slab required to achieve an STC of 53-55, structural deflection is

Staggered wood blocking one slze smaller than the framing, glued and end nalled. Locate blocks at the mid point for spans greater than 10', at the one third points for spans greater than 18', and at the one quarter points for spans greater than 25 . Cut blocks to within $1 / 8$ " of the space and glue.

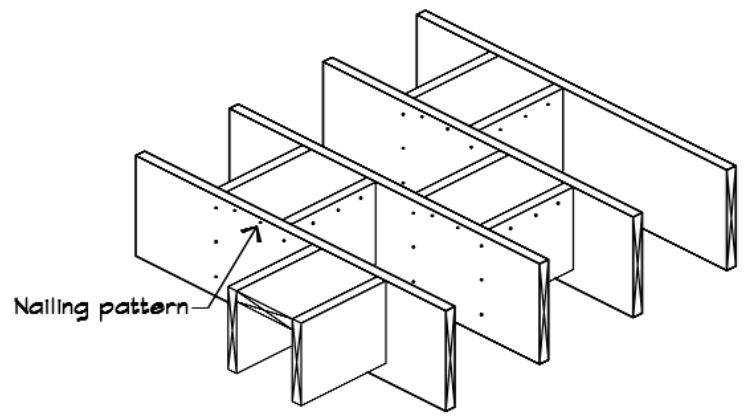

Fig. 3. Stepped-blocking in $2 x$ joist systems rarely a problem for moderate spans. In wood structures, the most common type of minimum quality construction consists of $1.5 \mathrm{inch}(38 \mathrm{~mm})$ lightweight concrete on plywood on joists with ceilings of drywall on resilient channel. This construction can transmit considerable low-frequency noise, since for normal joist lengths the deflection of a resilient channel is not sufficient to overcome the deflection of the joists.

In wood construction, both stiffness and damping can be increased by using the stepped blocking shown in Fig. 3 . The blocking works for several reasons. The first is the damping added by the moment connection provided by the glued faces and end nailing. Second, stiffness is increased by building the equivalent of another beam in the middle of the joist system. The third effect is additional load spreading, which distributes a point load among several joists and helps increase the composite floor stiffness. Stepped blocking is more effective than doubling joists or reducing joist spacing, although the two can be combined to good effect.

When prefabricated truss joists are used, a spacer plate must be installed as in Fig. 4. Stepped blocking should be located at the mid-span in joists having a length of between 10 to 18 feet $(3-5.5 \mathrm{~m})$ and at the one-third points in joists greater than 18 feet.

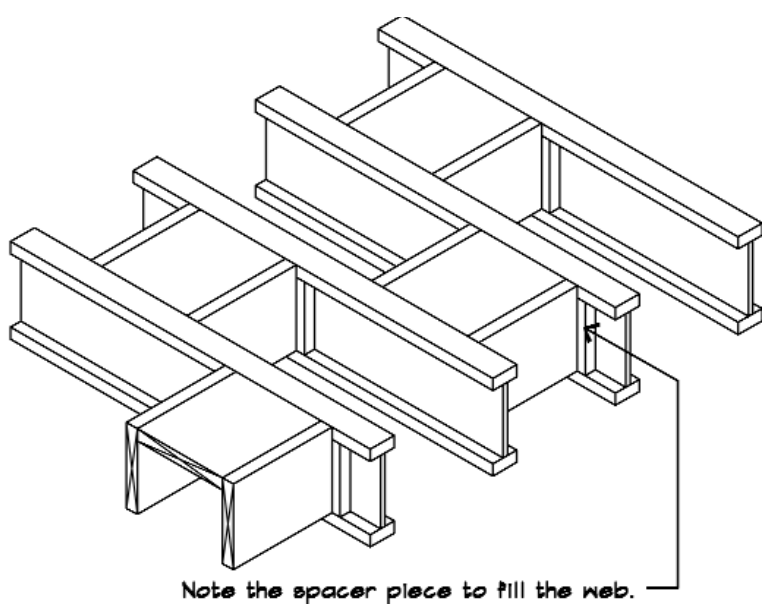

Fig. 4. Stepped-blocking in TJI joist systems

\section{Structural decoupling}

If a floor-ceiling system is not a monolithic slab, it generally includes an independently supported ceiling, which may be isolated vibrationally from the structure. In concrete construction the most common support system is hanger wires at $4 \mathrm{ft}(1.2 \mathrm{~m})$ on center wrapped around $11 / 2$ inch $(38 \mathrm{~mm})$ carrying channel (black iron) to which $7 / 8$ inch $(22 \mathrm{~mm})$ metal furring channels (hat channels) are wire tied. This system provides some isolation because it uses a point connection rather than a line connection. It can be further improved by utilizing vibration isolators either in the form of neoprene hangers or steel spring isolators cut into the hanger wires.

In wood structures, the most common type of structural decoupling has been resilient channel. At high frequencies, resilient channel can provide some improvement to the 


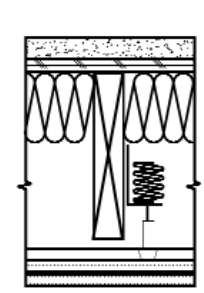

$11 / 2^{\prime \prime}(40 \mathrm{~mm})$ Lightwelght Concrete

$(12.8 \mathrm{lbs} / \mathrm{sq}$ pt or $63.4 \mathrm{~kg} / \mathrm{sq} \mathrm{m})$

1 Layer $5 / 8$ " (16 mm) Plywood

$2 \times 10(240 \mathrm{~mm})$ Wood Jolsts

R-11 Batt Insulation

1" (25 mm) Doplection Spring Isolators

2 Layers $3 / 8^{11}(16 \mathrm{~mm})$ Gypsum Board

A - Carpot on $3 / 8$ " (10 mm) Hair Pad

8 in 0 0 8 in 0

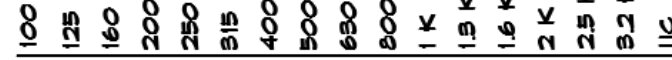

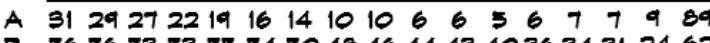

B 3636333333343048464443403634312462

Fig. 5. Spring-isolated ceiling systems

structural isolation; at very low frequencies; however, it is not particularly effective. Neoprene mounts, which include a clip to support hat channels, have recently become available. These give somewhat better floor isolation than resilient channels (STC 61 vs STC 53) and can support a double layer of drywall. They are installed on 24 inch (0.6 $\mathrm{m})$ centers in one direction and at the joist spacing (typically 16 inches or $0.4 \mathrm{~m}$ ) in the other. They provide the advantages of a resilient point-mount support along with ease of installation.

The most effective structural decoupling in wood floorceiling systems is a resiliently supported ceiling hung from spring hangers shown in Fig. 5 (STC 73). Note that the hangers are located high on the joist to preserve as much ceiling height as possible. Spring hangers are more effective than a ceiling supported on separate joists since with the latter system there is still the possibility of structural transmission through the joist supports. When a spring-hung ceiling is installed, unless the springs are precompressed, it will drop by the amount of the hanger isolator deflection. Hence, the ceiling drywall must not extend beyond the top of the wall drywall or else the walls will support its weight and the ceiling will bow. Once the ceiling has come to its final elevation the gap between the ceiling and wall material may be caulked. Molding or other trim pieces can then be added since they are non-bearing.

Spring precompression can minimize the actual deflection; in practice, however, this is somewhat tricky since the final load must be determined carefully. Springs are located at $4 \mathrm{ft}(1.2 \mathrm{~m})$ on center and if they support $16 \mathrm{sq} \mathrm{ft}(1.5 \mathrm{sq}$ $\mathrm{m})$ of ceiling, at $5.5 \mathrm{lbs} / \mathrm{sq} \mathrm{ft}(27 \mathrm{~kg} / \mathrm{sq} \mathrm{m})$, they will each carry about $90 \mathrm{lbs}(41 \mathrm{~kg})$. A spring located along an edge will carry a little more than half that load and one in a corner somewhat more than one quarter. In irregularly shaped ceilings or one with coffers and light fixtures the loading is more complex. It is prudent to have springs of several different sizes at a job site in case the odd hanger is needed. When stepped blocking and a resiliently hung ceiling are used in combination, the black iron can run parallel to the joists just below the blocking. The hat channels run perpendicular to the joists just below them. When the drywall is installed, its weight will pull the hat channel away from the joists so it does not touch.

Floors should be structurally decoupled laterally as well as vertically. Joists should not be run continuously across a party wall separation but should be supported on the nearest side of the party wall framing.
Floor squeak

Creaking floors are caused by the relative motion of wood on wood or nails rubbing against diaphragms, joists, or metal joist hangers. One common cause is shiners, as they are called-nonbedded nails that lay along side a joist and rub as the floor structure deflects. These must be removed before any lightweight or other concrete fill is poured.

Another cause is unevenness in the top surface of the joists, either due to imperfections in the wood or in the case of joist hangers, to differences in the joist level, which allows motion of the floor diaphragm against the nails. Gluing the plywood diaphragm to the joists prevents much of this panel motion and increases damping. Joists can also be shimmed at the hanger to assure even floor support. In tongue and groove flooring the individual planks can move relative to one another. Applying paraffin to the plank edges helps prevent this cause of squeak.

In some cases, subflooring, made of wood strands bonded together with a resin material, has been found to contribute to floor squeak. When these materials deflect, they rub against the nails that powder the binder and open up a small hole around the nail. This in turn loosens the grip of the nail on the board. This effect can be offset somewhat by gluing under the flooring and using a gripping ring shank nail. Ring shank nails are recommended for nailing all wood diaphragms since they provide some additional grip on the plywood. To repair existing wood floors screws can be added to cinch down the flooring to the joists and reduce panel movement. Glue should be applied from below along the top edges on both sides of the joists.

\section{Summary}

The achievement of adequate isolation between dwelling units is becoming more routine with the recognition of the factors influencing noise transmission and with the introduction of products on the market that provide vibrational separation between floor-ceiling components. While the use of each of the techniques cited above does not guarantee a perfect result, the author has used them to improve the isolation between spaces in multifamily dwellings and achieve results in line with the standards recommended in this article.

Where dwelling units are separated by design, good results can be achieved without complicated construction techniques. For example, in multifamily dwellings a townhouse plan is preferred over stacked units to avoid common floor-ceilings. When multi-story units are necessary, a plan that stacks similar rooms, one above another, avoids incompatible uses such as a bathroom located above a bedroom. Closets and other non-sensitive spaces can be located on party walls to provide additional shielding.

Modern buildings are constructed from lightweight materials, usually wood or light gauge steel studs, and the sound transmitted between spaces can be relatively high. In the older masonry and concrete structures, the mass law of building acoustics insured that sound isolation would be very good. The exigencies of cost and time have pushed building construction towards lighter and cheaper materials, and hence to greater sound transmission. Given these very real constraints, it is incumbent upon architects and engineers to find ways of providing adequate sound isolation in residential structures 
using commonly available and affordable materials.

Finally, we should not be lulled into a sense of complacency by compliance with minimum code standards. These standards are so poor that they do not yield a quality result. Instead, we should design to the reasonable expectation of a buyer. When better buildings become available they will command a higher value in the marketplace and reward a builder for his or her efforts.AT

\section{References}

1 Portions of this article have appeared in the author's book, Architectural Acoustics, published by Academic Press (2006). These are reproduced with permission.

2 Although this example is real, the names and locations have been altered.

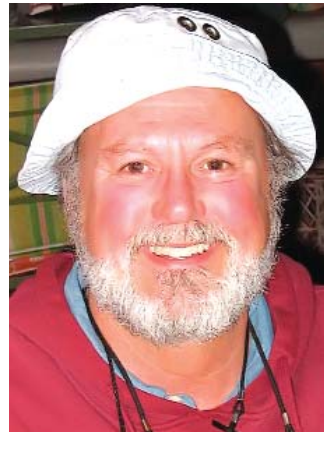

Marshall Long received a BSE from Princeton University in 1965, attended the University of Grenoble in France and the University of Madrid in Spain in 1966, and received MS and $\mathrm{PhD}$. degrees in engineering from UCLA in 1971. While still a graduate student, he founded his own consulting firm now in its 35th year. Marshall Long/Acoustics specializes in architectural acoustics, audiovisual design, noise and vibration control, and other technical areas related to acoustics. He enjoys sailing, judo, soccer, reading, and writing, and is living happily ever after with his family in Sherman Oaks, CA.

\title{
ASA at 75
}

\section{A snapshot of the Acoustical Society of America on its $75^{\text {th }}$ Anniversary ... diffusing knowledge in acoustics and promoting its practical applications for three quarters of a century}

\author{
William J. Cavanaugh and Henry E. Bass, Editors
}

To commemorate the Acoustical Society of America's $75^{\text {th }}$ Anniversary in 2004, the Committee on Archives and History arranged to record the history of the Acoustical Society of America and the technical areas covered by the Society's thirteen Technical Committees. History lectures covering the technical areas were presented at meetings of the Society by distinguished members of the acoustics community. The lectures have now been published in a commemorative volume titled ASA at 75 .

This 247 page paperback includes eighteen chapters covering the history of the Society, the development of the Technical Committees and Technical Council, the Society's Publications, Education in Acoustics, Standards and the technical areas. Each of the technical area chapters includes a time line denoting significant milestones in the development of the field. Some chapters contain illustrations, historical photos and bibliographies.

A 40-minute film titled "Acoustical Society of America-Celebrating Our $75^{\text {th }}$ Year" was premiered at the $75^{\text {th }}$ Anniversary Meeting. The film contains segm ents of reminiscences by past presidents of the Society and footage from a film recorded during the banquet at the $25^{\text {th }}$ Anniversary meeting in 1954. A copy of this film, in DVD format, will be included with the book (VHS format is available for an additional \$5).

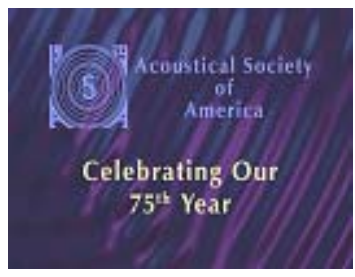

Price: $\$ 25$ to U.S. addresses; $\$ 35$ to non-U.S. addresses. Add $\$ 5$ for VHS formatted file (postage and hand ling included). Orders must be prepaid by check in U.S. funds or by Visa, Master Card or American Express credit card. Order from: Acoustical Society Publications, P.O. Box 1020, Sewickley, PA 15143-9998; Tel.: 412-741-1979; Fax: 412-741-0609.

\section{Visit asa.aip.org/map_publications.html for other available publications}

